\title{
A Combined Analysis of Airborne Particulate Pollutants Exposure and its Potential Risk
}

\author{
D. SARALA THAMBAVANI* and J. MAHESWARI ${ }^{\mathrm{a}}$
}

*Department of chemistry, Sri Meenakshi Govt College for Women, Madurai-625002, Tamilnadu, India

${ }^{a}$ Department of Chemistry, V. H. N. S. N. College, Virudhunagar-626001, Tamilnadu, India sarala_dr@yahoo.co.in

Received 10 June 2012 / Accepted 7 July 2012

\begin{abstract}
Atmospheric air quality deterioration is the one of the most significant environmental concern both developed and developing countries. In this study ambient air was monitored at regular intervals to assess gradients of air pollutants to evaluate the impact of particulate pollutants on human health. In atmospheric pollution monitoring, sampling is the first part of the study. Sampling of pollutants is especially difficult work and the automated instruments used for this purpose. The study was undertaken at Virudhunagar in Tamilnadu (India) and ambient air was monitored at 3 sites. Levels of particulate pollutants $\mathrm{PM}_{10}$ and $\mathrm{PM}_{2.5}$ were higher during the whole study period with more contribution during summer compared to other seasons. Potential risk to the population was analyzed by collecting data from hospitals and analyzed with particulate pollutant concentrations. Mean values of common respiratory diseases observed in the study area were statistically analyzed and related to particulate pollutant levels. Use of regression and correlation results provides insights to guide in assessing intra-urban air quality impacts. Diseases like asthma $(\mathrm{r}=0.9)$ and common cold $(\mathrm{r}=0.7)$ showed highest positive correlation with $\mathrm{PM}_{10}$.And $\mathrm{PM}_{2.5}$ showed significant positive correlation with the mean value of patients suffered from asthma. Taken together with previous studies the study provides additional evidence that long-term exposure to poor air quality is a hazard to the public health. The result indicated that, a need of an effective air pollution control policy keeping in view the detrimental effects of the particulate pollution in the study area.
\end{abstract}

Keywords: Air pollution, $\mathrm{PM}_{10}, \mathrm{PM}_{2.5}$, Potential risk, Asthma, Correlation

\section{Introduction}

Over the centuries air pollution has increased from a local nuisance to a global problem ${ }^{1}$. Pollution of air as a result of man's activities has been a feature of the urban environment for the centuries, probably since the introduction of fire as a means of heating and cooking. ${ }^{2}$ The urban air quality is continuously affected by emission from both stationary and mobile combustion source. The initial step toward improving air quality is the monitoring of the atmospheric air. Haze in an air pollution condition formed due to the presence of very fine dust, mist, fumes and so on in the atmosphere ${ }^{3}$. Particulate pollution is one of the most 
threatening problems due to the links between PM emissions and health effects ${ }^{4-6}$. Among the particles, those having median diameters higher than $10 \mu \mathrm{m}$ are stopped in the upper areas of the respiratory system. Smaller particles with median diameters less than $10 \mu \mathrm{m}$ $\left(\mathrm{PM}_{10}\right)$ can reach the lungs and provoke respiratory problems ${ }^{7}$, depending on their physicochemical properties. The smallest ones, with diameters less than $2.5 \mu \mathrm{m}$ reach the bronchial alveolus and may have long residence time inside, increasing health effects such as asthma and respiratory allergies ${ }^{8}$. The issue of urban air quality in particulate matter concentration receiving more attention. Therefore there is an urgent need to prepare strategies to control the PM emissions ${ }^{9}$.

The study was planned to asses the concentration of particulate pollutants at selected monitoring locations in study area. Generally the term particulate refer to all atmospheric substance that is not gases. Particulate can be composed of inert or extremely reactive material ranging in size from $100 \mu \mathrm{m}$ down to $1 \mu \mathrm{m}$ and less. The main sources for ambient particulate concentration at urban road ways are vehicle exhausts, resuspension from road dust. PM in the coarse mode produced by mechanical process such as soil dust, cloud droplets and many biological particle and a fine mode dominated by both primary anthropogenic pollution from combustion processes and gas-to-particle conversion ${ }^{10,11}$. Particulate pollution especially the fine fractions are of primary concern due to their direct impact on human health. However other pollutants are also as important, because their presence results in secondary contribution to $\mathrm{PM}$ pollution, for example $\mathrm{SO}_{2}$, $\mathrm{NOx}$ emission, following chemical transformation contribute significantly to fine PM fraction and this secondary contribution is as high as 40 percent $^{12}$. Due to the links between PM emissions and health effects ${ }^{4-6}$ it is necessary to measure the particle characteristics. Dust particles of size 2.5 -10 microns constitute fine dust particle remain suspended in the air and get entry in to the respiratory tract and pulmonary system of human beings and have a long term effect on health ${ }^{3}$.

Road vehicles emit various pollutants and this continuous discharge of pollutants creates a problem. This demand for making provision and efficient use of pollution control measures to minimize the adverse environmental impacts.The aim of this study was to quantify the exposure of people in the study region to ambient air pollution levels and explore any relationship between various common diseases and ambient pollution levels.

The Virudhunagar town is situated in the southern part of Tamilnadu and this is the administrative head of Virudhunagar district. Total vehicular population on April, 2009 was 29,726 and witnessed a tremendous increase of registration of vehicles from 2005 to 2009. Drainage construction, damaged roads and climatic conditions are the other main sources of severe dust pollution in this area and these cause problems like nasal and throat infection, continuous cold and asthma. Keeping all these in consideration, a study was initiated to monitor particulate pollutants of different sites in Virudhunagar town and its effects on human health.

\section{Experimental}

The present research work was mainly confined in Virudhunagar which is in southern part of Tamilnadu, India. It is a selection grade Municipality, spread over an area of 6.39 sq.km holding a population of 72,081 as of 2001(adopting population projection, it is interpolated the population of this town was 77449 in 2009). It is located at $9^{\circ} 35^{\prime}$ North latitude and 77 $57^{\prime}$ 'East longitude and $101.3 \mathrm{~m}$ above mean sea level. The climate of the town is hot and dry throughout the year with April and May being the hottest months. The maximum temperature 
is above $38.5{ }^{\circ} \mathrm{C}$, the minimum temperature is below $34.2{ }^{\circ} \mathrm{C}$. The town receives rainfall mostly during Northeast monsoon, and the average rainfall is $780 \mathrm{~mm}$ per annum. For this study three sampling stations were selected and these stations were Madura coats colony (site-1), Pavaly (site 2), Perali (site 3). The selected locations categorized as residential area, Heavy traffic area and Industrial area respectively.

\section{PM measurements}

Sampling constitutes the main part of the examination of air quality, such as location of sampling station, size of the sample, duration and rate of sampling ${ }^{13}$.The method for sampling of particulate pollutants is based on the size of the particles to be sampled ${ }^{14}$. The period of measurement ranges from may 2010 to may 2011. From the study locations, air samples were collected on the basis of 24 hours average and the samples were analyzed in the laboratory. The parameters monitored for ambient air quality were suspended particulate matter $\left(\mathrm{PM}_{10}\right)$, Respirable particulate matter $\left(\mathrm{PM}_{2.5}\right)$, of ambient fine dust sampler model APM-415 of envirotech with provisions for particulate sampling. Particulate matters collected separately in a preweighed glass fibre filter paper on 24 hour average drawing air flow at $1.1 \mathrm{~m}^{3} / \mathrm{min}$.

\section{Data collection}

Study area has number of hospitals and the health survey taken from number of hospitals however for the present study the data obtained from government hospital of Virudhunagar only considered for statistical interpretation. The data for common diseases due to respiratory problems for the years 2010 and 2011 were obtained. Data collection programme was held every month .The data collected so monthly are subjected to statistical analysis to get an idea of the particulate pollutants concentration and its health impacts. Analysis of variance (ANOVA) is used to study the significance of mean values of samples collected at the same time.

\section{Results and Discussion}

We have estimated number of people suffering from diseases per year attributable to air pollution. The mean values of particulate matter concentration in $\mu \mathrm{g} \mathrm{m}^{-3}$ were at $95 \%$ confidence intervals. Analysis of variance revealed significant difference between these means $(\mathrm{p}<0.001)$.

\section{Effects of air pollution on human health}

In a study of six regions of Sao Paulo, Brazil, Martins et. al, ${ }^{15}$ suggested that socio economic deprivation represents an effort modifier of the association between air pollution and respiratory deaths in elderly people for an increase of $10 \mu \mathrm{g} \mathrm{m}^{-3}$. Murty et. al. ${ }^{16}$ finds that the annual damages from the morbidity effects of air pollution of Delhi is of the order of Rs.4896.6 million. In a study it shows that $\mathrm{PM}_{2.5}$ is more dangerous for human health and responsible for several cardio vascular and respiratory diseases such as asthma and bronchitis. Lipmann ${ }^{17}$ estimated that the total mortality increased by approximately $1 \%$ for every 10 in $\mu \mathrm{g} \mathrm{m}^{-3}$ increase in $\mathrm{PM}_{2.5}$ concentrations. It was reported that in four out of five studies in Europe and US exposure to higher out door level of $\mathrm{PM}_{10} / \mathrm{PM}_{2.5}$ vehicle traffic and $\mathrm{NO}_{2}$ are associated with significantly higher risk of lung cancer. Pandey et. al. ${ }^{3}$ studied the relationship between the rates of hospitalization due to acute respiratory events and acute coronary events and ambient air quality. A few studies ${ }^{18-19}$ carried out in other parts of the country have looked in to the adverse health effects of air pollution. 
A health study done by Kamat and Doshi showed a higher morbidity in subjects residing in areas with raised pollution levels ${ }^{18}$. There are many potential explanations for the seemingly small impact of particulate pollution on mortality in Delhi ${ }^{19}$. It is stated in a study, it is unclear whether air pollution contributes to the development of asthma, but it has been found that air pollution does trigger asthma episodes ${ }^{20}$. Evidence suggest that short term and acute exposure to air pollutants leads to aggravation of symptoms and deterioration of lung function in patients with asthma and chronic obstructive lung disease is substantial and more definitive ${ }^{21}$.

Table 1 shows the monthly average values of $\mathrm{PM}_{10}$ and subjects of this area suffered from common respiratory diseases. It must be stated here that even the residential area had very high particulate levels. The impact of air pollution on health outcome was measured as respiratory diseases like common cold, wheezing, asthma, sneeze, cough, bronchitis. Among in most age groups cough and sneeze are common in residents of Virudhunagar, India.

Table 1. Monthly average concentration of $\mathrm{PM}_{10}$ and correlation co- efficient with common respiratory diseases

\begin{tabular}{cccccccc}
\hline & & \multicolumn{5}{c}{ No. of peoples suffered from } \\
\cline { 3 - 7 } & PM $_{10}$ & Cold & Wheezing & Asthma & Sneeze & Cough & Bronchitis \\
\hline May'10 & 197.3 & 900 & 310 & 75 & 720 & 677 & 400 \\
Jun'10 & 191.2 & 892 & 300 & 70 & 711 & 670 & 396 \\
Jul'10 & 185.4 & 890 & 287 & 68 & 701 & 660 & 390 \\
Aug'10 & 176.0 & 870 & 270 & 65 & 698 & 650 & 386 \\
Sep'10 & 159.9 & 855 & 254 & 62 & 680 & 646 & 380 \\
Oct'10 & 151.0 & 849 & 240 & 61 & 650 & 638 & 374 \\
Nov'10 & 159.7 & 850 & 220 & 60 & 620 & 623 & 372 \\
Dec'10 & 192.6 & 847 & 219 & 63 & 610 & 613 & 369 \\
Jan'11 & 199.0 & 869 & 221 & 70 & 630 & 620 & 375 \\
Feb'11 & 234.2 & 872 & 224 & 74 & 650 & 628 & 378 \\
Mar'11 & 248.3 & 891 & 250 & 76 & 698 & 632 & 385 \\
Apr'11 & 254.4 & 902 & 290 & 79 & 703 & 644 & 392 \\
& $\mathrm{R}$ Values & 0.7 & 0.1 & 0.9 & 0.3 & -0.1 & 0.3 \\
& $\mathrm{R}^{2}$ value & 0.43 & 0.02 & 0.82 & 0.08 & 0.01 & 0.10 \\
\hline
\end{tabular}

Concentration of $P M_{10}$ in $\mu \mathrm{g} \mathrm{m}^{-3}$

However cough, sneezing and wheezing, showed no consistent pattern with regard to their association with air pollution. The correlation coefficients were also showed no significant correlation. The regression coefficient values shows there is strong positive correlation between concentration of $\mathrm{PM}_{10}$ and acute asthma. Figure 1 and Figure 2 show the significant positive correlation exists between diseases like asthma, common cold and particulate matter $\mathrm{PM}_{10}$ respectively. This is supported by studies have been carried out in the last few years ${ }^{22-25}$. According to their studies asthma prevalence was strongly associated with air pollutants. 


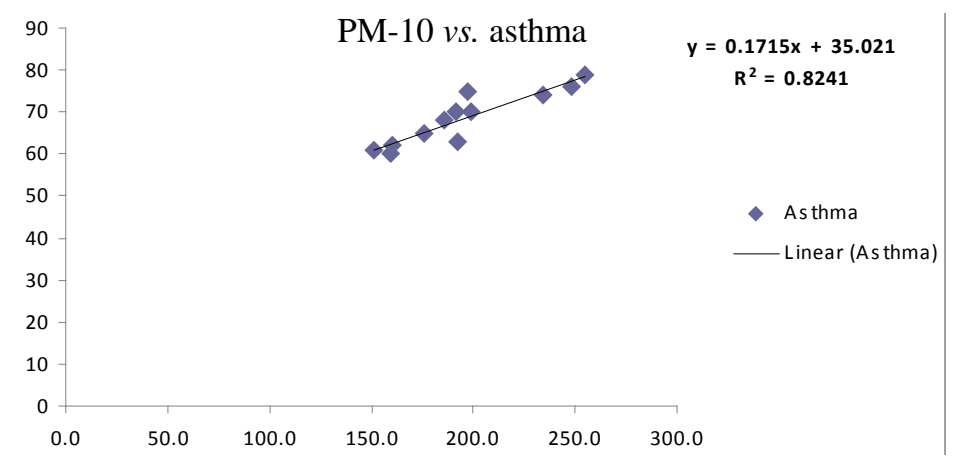

Figure 1. Correlation graph of $\mathrm{PM}_{10}$ with number of asthma patients

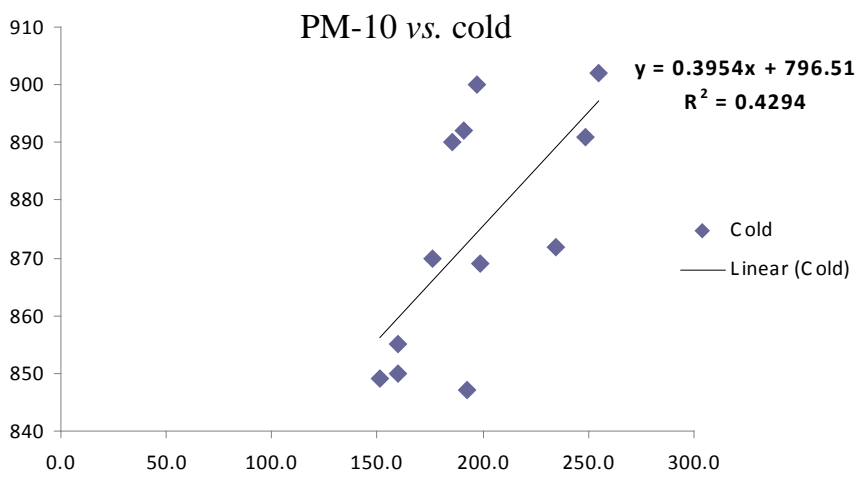

Figure 2. Correlation graph of $\mathrm{PM}_{10}$ with number of peoples suffered from common cold

Table 2 shows the monthly mean values of the $\mathrm{PM}_{2.5}$ and common respiratory diseases. A positive, significant relationship exists between particulate pollution $\mathrm{PM}_{2.5}$ and asthma patients. Figure 3, shows positive correlation exists between asthma and particulate matter $\mathrm{PM}_{2.5}$.

Table.2. Monthly Average values of $\mathrm{PM}_{2.5}$ and correlation coefficients with common respiratory diseases

\begin{tabular}{|c|c|c|c|c|c|c|c|}
\hline & \multirow[b]{2}{*}{$\mathrm{PM}_{2.5}$} & \multicolumn{6}{|c|}{ No. of peoples suffered from } \\
\hline & & Cold & Wheezing & Asthma & Sneeze & Cough & Bronchitis \\
\hline May‘10 & 83.97 & 900 & 310 & 75 & 720 & 677 & 400 \\
\hline Jun'10 & 82.63 & 892 & 300 & 70 & 711 & 670 & 396 \\
\hline Jul'10 & 81.53 & 890 & 287 & 68 & 701 & 660 & 390 \\
\hline Aug'10 & 75.77 & 870 & 270 & 65 & 698 & 650 & 386 \\
\hline Sep'10 & 60.23 & 855 & 254 & 62 & 680 & 646 & 380 \\
\hline Oct'10 & 59.60 & 849 & 240 & 61 & 650 & 638 & 374 \\
\hline Nov'10 & 108.30 & 850 & 220 & 60 & 620 & 623 & 372 \\
\hline Dec'10 & 105.67 & 847 & 219 & 63 & 610 & 613 & 369 \\
\hline Jan'11 & 103.70 & 869 & 221 & 70 & 630 & 620 & 375 \\
\hline Feb'11 & 106.63 & 872 & 224 & 74 & 650 & 628 & 378 \\
\hline Mar'11 & 109.30 & 891 & 250 & 76 & 698 & 632 & 385 \\
\hline Apr'11 & 109.03 & 902 & 290 & 79 & 703 & 644 & 392 \\
\hline & R Value & 0.20 & -0.33 & 0.48 & -0.32 & -0.52 & -0.16 \\
\hline & R2 value & 0.04 & 0.11 & 0.23 & 0.10 & 0.27 & 0.03 \\
\hline
\end{tabular}




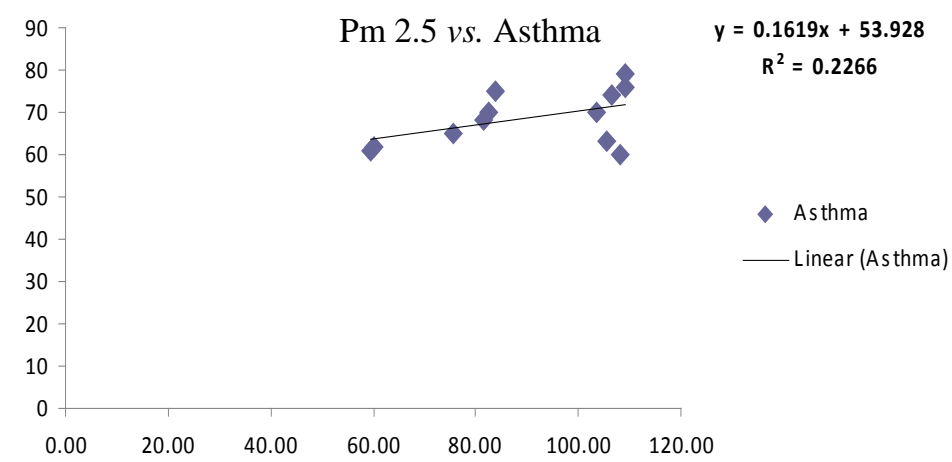

Figure 3. Correlation graph of $\mathrm{PM}_{2.5}$ with number of asthma patients

The frequency of respiratory infections in past one year in asthmatics was significantly more. The study suggests that worst road condition and unplanned traffic and increase in number of open modes of travel leads to high exposure of air pollutants especially particulates ,consequently increasing the risk of respiratory health damage significantly.

\section{Conclusion}

From the results, it can be concluded that particulate matter is the main pollutant in Virudhunagar. The reason is being the growing number of automobiles and coarse roads with congested traffic. The study reveals that air pollutants have adverse effects on human health. The associations are of a casual nature should take it seriously and there is a need for policy related decisions to be implemented with view to curb the menace air pollution in this area and improve public health. Overall, the study provides additional evidence that poor air quality is an important public health problem. The following suggestions may be given to improve the air quality in the study area

- This problem can be overcome by adapting advance eco-friendly transport systems, eco-friendly fuels and widening of roads.

- Proper environmental awareness and personal protective devices may be useful in avoiding health problems.

- Further studies on the impact of long term exposure of poor air quality with respect to possible effects on human health are needed.

- To assess the impacts of the air quality, it is clear that there is an urgent need for more rigorous air quality monitoring and also use of consistent methodologies.

- The different components of particulates with relation to health effects should be undertaken.

- Association between air pollution and adverse health effects is influenced by several potential and real confounders such as overcrowding, poverty, smoking, malnutrition, indoor air pollution and lack of access to health care and all these factors need to be carefully monitored and considered in future studies.

\section{Acknowledgment}

Authors wish to acknowledge the managing board of VHNSN College, Virudhunagar for providing the opportunity to do research work. The authors also thank the Head, Dept. of Chemistry for his valuable moral support. 


\section{References}

1. $\quad$ Emberlin J, J Europian Resir Rev., 1998, 53, 164-167.

2. $\quad$ Sayadi A R, Sayadi M H and Shabani Z, Poll Res., 2011, 30(2), 251-256.

3. Pandey A, Kumar, Pal A, Singh N and Yunus M, Indian J Environ Protect., 1998, 19(3), 181-184.

4. Peters A, Wichman H E, Tuch T, Heinrich J and Heider J, Am J Respiratory Critical Care Medicine, 1997, 155, 1376-1383.

5. $\quad$ Pope III C A and Dockery D W, J Management Association, 2006, 56, 706-742.

6. Somers C M, Mc Carry B E and Malleck F and Quinn J, Science, 2004, 304, 1008-1010.

7. Healy D, Silvari V, Whitekar A, Lopez J, Pere Trepat E and Heffron E, In Proceedings of the $6^{\text {th }}$ International Conference on Urban air Quality, Limassol, Cyprus, 2007.

8. Avnish Chauhan, Mayank Pawar, Rajeev Kumar and Joshi P C, J Am Sci., 2010, 6(9), 565-573.

9. Srimuruganandan B and Sargar Madanayak S N, Atmospheric Pollution Research, 2010, 1, 184-194.

10. Friedlander S K, Smoke, Dust and Daze Fundementalss of Aerosol Dynamics, $2^{\text {nd }}$ Edition, Oxford University Press, 2000.

11. Almeida S M, Pio C A, Freitas M C, Reis M A and Tancoso M A, Atmospheric Environment, 2005, 39, 3127-3138.

12. Saratha K Guttikunda and Rakesh Agarwal, Indian J Air Pollut Control., 2009, 9(1), 37-46.

13. Chaloulakou A, Kassomenos P, Spyrellis N, Philip Demokritou and Koutrakis P, Atmospheric Environment., 2003, 37, 649-660.

14. Rao C S, Air Pollution, Wiley Easten, New Delhi, 1993.

15. Martins M C, Fatigati H FL, Vespoli T C, Pereira L A A, Martins M A, Saldiva P H N and Braga A.L.F. Journal of Epidemiology and Community Health, 2004, 58, 41-46.

16. Murty M N, Gulati S C and Banerjee A. Discussion Paper No. 62/2003. Institute of Economic Growth, Delhi.

17. Lippmann M, Royal Society of Chemistry, U K, 1998, 10, 75-99.

18. Kamat S R and Doshi V B, Eur J Epidemiol. 1987, 3, 265-277.

19. National Capital Territory of Delhi (1991), Registration of Births and Deaths Act 1969: AnnualReport 1991, Bureau of Economics and Statistics and Office of the Chief Registrar (Births and Deaths).

20. Abelsohn A, Stieb D, Sanborn M D and Weir E, Outdoor Air Pollution, CMAJ 2002, 166(9),1161-1167.

21. Chhabra S K, Chhabra P, Rajpal S and Gupta R K, Environ Health, 2001, 56, 58-64.

22. Chowgule R V, Shetye V M, Parmar J R, Bhosale A M, Khandagale M R, Phalnitkar S V and Gupta P C, Am J Respir Crit Care Med., 1998, 158, 547-554.

23. Awasthi S, Glick H A, Fletcher R H and Ahmed N, Indian J Med Res., 1996 104, 257-262.

24. Lahiri T, Roy S, Basu C, Ganguly S, Ray M R and Lahiri P, Indian J Med Res., 2000, 112, 21-26.

25. Patel A B, Williams S V, Frumkin H, Kondawar V K, Glick H and Ganju A K, Indian J Occup Environ Health, 2001, 7, 119-126. 